\title{
A cultura profissional do psicólogo e o ideário individualista: implicações para a prática no campo da assistência pública à saúde
}

\author{
Magda Dimenstein \\ Universidade Federal do Rio Grande do Norte
}

Resumo

Objetiva-se refletir acerca de alguns elementos que definem a cultura profissional do psicólogo no Brasil, bem como nos seus efeitos sobre as práticas realizadas nas instituições públicas de saúde. O “sujeito psicológico", modelo de subjetividade pregnante entre os psicólogos, é um desses elementos definidores da sua cultura profissional, representação desenvolvida a partir do ideário individualista e da difusão dos saberes "psi” na nossa sociedade. A hegemonia dessa concepção de subjetividade tem conseqüências importantes para as práticas realizadas nas instituições públicas de saúde, entre as quais destacam-se: conflito entre as representações de saúde/ doença entre usuários e profissionais; baixa eficácia das terapêuticas e alto índice de abandono dos tratamentos; seleção e hierarquização da clientela. Por outro lado, configura-se enquanto obstáculo à criação de uma "cultura avaliadora" entre os profissionais e à construção de instrumentos que permitam ao psicólogo avaliar continuamente o funcionamento dos serviços e práticas nas instituições públicas de saúde.

Palavras-Chave: Cultura profissional, subjetividade, instituições públicas de saúde. 
Key words: Professional culture,

subjectivity, public health services.

\section{Abstract}

Psychologist's professional culture and individualistic values: consequences in the practices in public health services The aim of this paper is to reflect about some elements that are defining the professional culture of the psychologist in Brazil, as well as its effects upon the institutional practices in the public health service. The "psychological subject", model of subjectivity among psychologist is one of the defining elements of this professional culture, representation developed from the individualistic values and psi knowledge in our society. The hegemony of this conception of subjectivity has important consequences in the practices accomplished in the public health institutions, such as conflicts in the representations of health and illness between users and professionals; little efficiency in the therapeutic services and high index of desertion of treatment; hierarchies and discrimination among service users. On the other hand, there always appear obstacles to the creation of an "evaluation culture" among professionals and the construction of instruments that could allow the psychologist to continuously evaluate the quality of their services and practices in the public health institutions

ste trabalho tem como objetivo refletir acerca de algumas características da cultura profissional do psicólogo brasileiro ${ }^{1}$, tentando articulá-las com a crescente hegemonização da ideologia individualista vivida em nosso país desde os anos 60 - sobretudo a partir da difusão da psicanálise entre as classes médias urbanas - bem como pensar os seus possíveis efeitos sobre a prática dos psicólogos na assistência pública à saúde e em termos do modelo de subjetividade $^{2}$ com o qual trabalham.

Para tanto, vou procurar definir "cultura profissional"; que aspectos deste ideário individualista marcam a identidade e a cultura profissional do psicólogo no Brasil; qual o modelo de subjetividade 
veiculado pelo psicologismo ou "cultura psicanalítica" e, finalmente, pensar qual o impacto dessas concepções na determinação de um modelo profissional que tem conseqüências relevantes quando o psicólogo passa a atuar no campo da assistência pública à saúde.

O modelo hegemônico de subjetividade no campo psi ${ }^{3}$ : o "sujeito psicológico"

Pretendo, neste primeiro momento, discutir a seguinte questão: o modelo hegemônico de subjetividade no campo psi é o do sujeito psicológico, desenvolvido a partir do ideário individualista e engendrado pelos próprios saberes psi, podendo ser pensado como um dos efeitos da sua difusão.

A ideologia do individualismo representa um sistema de idéias, ou como disse Duarte (1988), uma tendência, uma corrente, um fluxo localizado de idéias e valores presente nos segmentos letrados e intelectualizados das classes médias das sociedades modernas, cujo acento recai sobre a categoria "indivíduo", não no sentido do agente empírico, membro e condição fundamental de qualquer sociedade, mas enquanto valor moral e jurídico (da cidadania, dos direitos e deveres universais), enquanto configuração abstrata calcada em valores como liberdade e igualdade ${ }^{4}$. Existe, portanto, a idéia de um indivíduo autônomo, senhor de si e independente, ou seja, ausente de vínculos e dos determinismos universalmente definidos pela cultura, que marca a ideologia ocidental moderna; idéia que se opõe, segundo a teoria dumontiana, àquela própria a sociedades tradicionais, hierárquicas e holistas. Nestas, por sua vez, a coletividade, as tradições e os costumes condicionam as existências individuais, isto é, as identidades são construídas a partir da posição ocupada no quadro social. Diferentemente, nas sociedades modernas predomina uma configuração particular - o indivíduo, moralmente autônomo, pré-social, despido de transcendência, possuidor de direitos e deveres - configuração impensável em contextos holistas, onde o todo social prevalece sobre as partes e onde não há uma oposição entre indivíduo e sociedade (Salem, 1992).

Este ideário, por sua vez, foi o que possibilitou a emergência de um campo de saberes psi e, conseqüentemente de um tipo de subjeti- 
vidade específica dentro das sociedades modernas, ou pelo menos, em um dos seus segmentos, a classe média urbana. Alguns autores brasileiros (Russo, 1993; Salem, 1992; Velho, 1987), assinalaram que apesar da sua enorme contribuição, as concepções de Dumont não são suficientes para dar conta sozinhas de uma outra face deste indivíduo moderno: a face psicológica, da interioridade, do autocultivo e da auto-estima, a qual foi reforçada com o advento da psicanálise e a difusão dos saberes psi na sociedade ${ }^{5}$.Vejamos o porquê disto.

Com a idéia do inconsciente, o que a psicanálise veio empreender foi a problematização e superação da visão consciencialista do ser humano, cujas implicações foram as idéias de que

o sujeito é movido por forças que desconhece; o verdadeiro sentido de suas experiências está onde sua consciência não pode chegar; ele é um trágico personagem sempre tentando compreender e interpretar as motivações desconhecidas que o governam (Bezerra, 1989, p. 232).

Assim, o indivíduo racional, autônomo, senhor de si, não passaria de uma ilusão, pois o inconsciente é justamente o que determina suas motivações e ações. A psicanálise, então, vem falar de um sujeito clivado, cindido, autodeterminado de dentro para fora; vem falar de um sujeito despossuído subjetivamente e dotado de uma interioridade psicológica singular, a qual está condenado e que o diferencia dos demais seres humanos.

Em outras palavras, a psicanálise passa a trabalhar com uma nova concepção de indivíduo: o sujeito psicológico, cuja verdade é a do seu desejo inconsciente. Dessa maneira, um dos seus efeitos foi engendrar uma concepção de subjetividade individualizada e individualizante, particular, singular a cada sujeito, mediada exclusivamente pela história pessoal de cada indivíduo. Entretanto, esta concepção de subjetividade só foi possível emergir num contexto historicamente datado e circunscrito, onde as idéias próprias ao ideário individualista vigoravam, isto é, a idéia de um indivíduo livre, independente, igual a todos os outros, porém singular, pois dotado de uma interioridade ímpar. Ou seja, estas idéias mantiveram-se vivas funcionando enquanto "representações ideais" ${ }^{6}$ muito poderosas que auxi- 
liaram bastante o processo de modernização que a sociedade brasileira começou a viver a partir dos anos 60 .

Figueira (1985), pensando sobre o processo de modernização da sociedade brasileira e a difusão da psicanálise, aponta como nos anos 60/70 a psicanálise se difundiu por diversas vias, atingindo um grau de popularização tão alto - o que chamou de cultura psicanalítica - que passou a funcionar como uma espécie de "visão de mundo". Para ele, esta cultura psicanalítica se expressa em três dimensões: eidos ou lógica para o pensamento, que consiste em procurar embaixo das aparências a verdade das coisas; ethos ou código de emoções, cuja ênfase recai na expressão das emoções mais íntimas e pessoais; e um dialeto ou modo de falar chamado de "psicotagarelice expressiva" (p. 8). Além disto, este processo de difusão da psicanálise teria vindo responder a uma necessidade social de orientação das pessoas afetadas pela modernização acelerada ${ }^{7}$ experimentada pela sociedade brasileira a partir da década de 1950, período em que ocorreram transformações políticas e desenvolvimento econômico e, cujo lema se fazia representar pelos ideais da mudança, modernização e progresso, altamente difundidos nas classes médias. Os trabalhos de Santos (1990) e Coimbra (1993) vieram apontar como a imagem da psicanálise ao longo dos anos 60/70 foi associada a movimentos de transformação social, constituindo-se numa estratégia de grande valor político. A ênfase na privatização e nuclearização da família, na responsabilidade individual de cada um dos seus membros, a ênfase nos projetos de ascensão social, na descoberta de si mesmo, na busca da essência e na libertação das repressões, foram algumas destas estratégias que culminou na promoção de uma psicologização do cotidiano e da vida social e num esvaziamento político ${ }^{8}$. Assim, a difusão destes ideais analíticos terminou por oferecer referenciais estéticos, modelos identificatórios, ou seja, produziu uma representação ideal de sujeito - o sujeito psicológico - e de práticas baseadas neste modo particular de subjetividade, que no caso dos psicólogos, tornaram-se hegemônicas e definidoras de sua identidade e cultura profissionais. Entretanto, outros autores e textos referem à existência, neste momento, de uma mudança no eixo do questionamento político que faz com 
que temas como a família, a vida sexual etc. sejam intensamente politizados. É como se o político mudasse de lugar (neste sentido, ver Castel, 1989).

Sem dúvida, é o sujeito psicológico que permeia os saberes e as práticas dos profissionais $\mathrm{psi}^{9}$, concepção que surgiu a partir destes saberes e que é compatível com o Zeitgeist da modernização da sociedade brasileira e disseminação dos ideais individualizantes. Porém, no meu entender, existe uma problemática ${ }^{10}$ em relação à hegemonia desta concepção de subjetividade no campo psi, na medida em que ela não é contextualizada, relativizada, ou seja, na medida em que ela é universalizada como se fosse o único modelo de subjetividade possível, desprezando-se assim, a complexidade e a multideterminação do processo de subjetivação. Acredito, então, que o predomínio de uma concepção de subjetividade tão específica entre os psicólogos devese ao amplo processo de difusão da psicanálise nas classes médias brasileiras, de onde, por sinal, provém a maioria deles, e conseqüentemente da sua adesão às representações ideais veiculadas nas Weltanschauungen psicanalíticas.

Com base nisto, vou procurar apontar a seguir, como algumas características da formação e da identidade profissional do psicólogo no Brasil têm relação direta com este processo de hegemonização do ideário individualista, de intensa difusão das teorias e práticas psi mediatizada pelos especialistas da área - e de um modelo específico de subjetividade. Antes, porém, gostaria de lançar uma questão para futuros debates: a Psicologia, nas suas diversas formas e facetas, é estrutural e congenitamente ligada à produção de uma certa subjetividade (individualizada, intimista etc.) ou há alguma coisa chamada "Psicologia" que transcende os determinismos históricos, sociais e culturais e pode, desse modo, voltar-se contra ou libertar-se do produto de seu modus operandi?

\section{A cultura profissional do psicólogo brasileiro}

É no campo da Sociologia das Profissões que se realizam investigações acerca dos conflitos e processos de poder existentes entre as diversas profissões na sociedade. Quatro elementos básicos compõem o que chamam de "profissionalismo": o processo de inserção 
histórica de cada profissão no mercado de trabalho; a formalização de um campo de saber e práticas através de legislações profissionais (mandato social); a institucionalização de organizações corporativas e a cultura profissional. A análise da relação entre tais elementos é fundamental para entendermos as práticas profissionais contemporâneas, os conflitos existentes e "as várias tentativas de 'usurpar' competências e de 'imperialismo' entre as profissões", tal como ressaltou Vasconcelos (1997, p. 29). Neste trabalho, vou destacar apenas um destes elementos: a cultura profissional.

Baseando-me em Vasconcelos (1997), entendo por cultura profissional o conjunto de idéias, visão de mundo e estilo de vida profissional adotado por um grupo profissional específico, que vem determinar a adesão e preferência por certos modelos de atuação, por certos referenciais teóricos, assim como, por certos padrões, códigos e regras de relacionamento entre os pares e com a comunidade leiga; além de definir suas formas de organização e representação na sociedade. A cultura profissional do psicólogo brasileiro deve ser pensada levando-se em consideração os seguintes aspectos: (a) história e ideologia da profissão em nossa sociedade; (b) condições em que se dá a formação em nosso país; (c) representação social da profissão e (d) população que procura os cursos de Psicologia no Brasil.

Situar historicamente o surgimento da Psicologia como um campo de saber autônomo e a instituição do profissional psicólogo foi tarefa empreendida por Yamamoto (1987). De forma sucinta, pode-se dizer que a Psicologia cresceu comprometida com o capital e o consumo, servindo principalmente de suporte científico das ideologias dominantes e de auxílio na perpetuação do status quo ao longo do seu percurso de legitimação social. Em função disso considera-se que a Psicologia muito pouco exerceu, e vem exercendo, um papel questionador e transformador das instituições e das relações pessoais e vem contribuindo mais para a reprodução das estruturas sociais e das relações de poder (Botomé, 1996; Gil, 1985; Martín-Baró, 1997). Segundo o ponto de vista de tais autores, na maior parte das vezes, o psicólogo não tem claro como o conhecimento que utiliza (técnicas e conceitos) é produzido e a quem beneficia, de maneira que termina 
contribuindo para o controle social da população. Isso começa na universidade, conforme aponta Botomé (1996), pela adesão cega a teorias, técnicas, modelos e rituais profissionais que condicionam determinadas classes de respostas, consideradas suficientes e adequadas para explicar os problemas independentemente de quem os apresenta e de suas características. Assim, o poder é exercido, encoberto por uma formação que em muito contribui para ausentar o profissional da sua responsabilidade social e pessoal.

Martín-Baró (1997), com base nos questionamentos de Richelle (1968) e Deleule (1972), entende que a proliferação de psicólogos nas diversas sociedades deveu-se

à função que estava assumindo na sociedade contemporânea, ao converter-se em uma ideologia de reconversão. A Psicologia oferecia uma solução alternativa para os conflitos sociais: tratava-se de mudar o indivíduo preservando a ordem social ou, no melhor dos casos, gerando a ilusão de que talvez, ao mudar o indivíduo, também mudaria a ordem social, como se a sociedade fosse uma somatória de indivíduos (Martin-Baró, 1997, p. 12).

No contexto brasileiro, os estudos realizados por Massimi (1990; 1996) sobre a história da Psicologia revelam que o ensino da psychologia nas escolas normais a partir da segunda metade do século XIX esteve voltado para "ensinar o indivíduo a adaptar-se às circunstâncias ambientais, assumindo valores relativos como normas para seu comportamento" e como a escola passou a ser um "laboratório de produção de cidadãos exemplares” (p. 36). Além disso, sua introdução nos currículos das faculdades de medicina do Rio de Janeiro e de Salvador deveu-se a um interesse de que ela pudesse oferecer meios para o controle social dos indivíduos e das populações e para a "patologização" do comportamento anormal, isto é, estava associada à resolução de problemas, desajustes e desvios da sociedade. O surgimento da Psicologia científica no início do século XX e a criação de inúmeros laboratórios experimentais e o desenvolvimento dos testes também visava oferecer um método mais objetivo para o conhecimento do homem, para a medição dos comportamentos e seu ajuste à ordem social vigente. Guimarães (1982) assinalou o enorme 
desenvolvimento e reconhecimento da Psicologia após a II guerra mundial e sua ligação com o movimento preventivista da psiquiatria americana com funções de prevenção e controle da loucura, assim como do bem-estar social e individual.

Dessa forma, a Psicologia foi conquistando espaço, sistematizando técnicas e saberes, legitimando-se perante a sociedade, fazendo sua história. Ela se inseriu no sistema jurídico buscando identificar delinqüentes desde a infância e prevenir futuros desajustes; no sistema educacional preocupando em identificar e solucionar problemas de aprendizagem e de ajustamento escolar e no sistema médico oficial auxiliando na prevenção de doenças físicas e mentais. Enfim, ela penetrou em toda a sociedade sem estar necessariamente comprometida com a produção de conhecimentos na perspectiva de transformação das práticas e ideologias dominantes em nossa sociedade. Caniato (1988), chegou a falar de uma "amnésia social" (p. 181) em que vivem os psicólogos, levando-os a muitas distorções teóricas, práticas descontextualizadas e uma psicologização dos problemas sociais, que os impedem de perceber o caráter histórico dos fenômenos sociais e suas implicações político-ideológicas.

Guimarães (1982) também apontou que a própria definição oficial da prática psicológica (Lei 4.119/62) veio atribuir uma tarefa de normatização e controle, de forma que a Psicologia seria então mais um recurso disciplinar,

no sentido de buscar um controle sobre os indivíduos com problemas de ajustamento para sujeitar suas forças no nível da docilidade-utilidade: os indivíduos devem ser olhados, vigiados, diagnosticados, tratados, disciplinados para trabalhar e atuar em prol da manutenção do sistema sócio-político vigente (1982, p. 14).

Já Mancebo (1997) assinalou que o empenho dos órgãos normatizadores em estabelecer um caráter científico ao currículo mínimo do curso de Psicologia, através do parecer 403/62 do Conselho Federal de Educação, revela claramente a influência positivista que ainda hoje pode ser observada. Certamente essa não é toda a história da Psicologia brasileira, mas é uma parte significativa que não pode ficar sem discussão quando se pensa a questão da profissão no país. 
Além desses aspectos, é do conhecimento geral que a maioria dos estudantes que freqüenta os cursos de Psicologia no país aspira ao ideal liberal de atuar com seus iguais, a classe média urbana, bem como ter uma formação teórica voltada para a clínica dentro do modelo tradicional do atendimento individual. Essa imagem da profissão é, portanto, a mais conhecida e valorizada pela categoria e pelo público leigo.

Os cursos de Psicologia têm se caracterizado ao longo dos anos por não possibilitar ao aluno o conhecimento dos aspectos sociais históricos, políticos e ideológicos - que determinam sua prática e a realidade em que atua. A Psicologia que é ensinada nas nossas universidades tem a pretensão de ser apolítica, neutra, e justo por isto está embebida da ideologia dominante e conservadora das relações sociais. Assim, é uma Psicologia ingênua e ineficaz que a universidade termina promovendo, porque psicologizante e a-crítica dos modelos importados, o que leva a um distanciamento do social e uma aproximação ainda maior do aluno às idéias e valores hegemônicos da ideologia individualista que ele carrega, pois oriundo das classes médias urbanas.

Nossos currículos, por sua vez, espelham e produzem um modelo hegemônico de atuação profissional - o modelo clínico liberal privatista, o modelo da psicoterapia individual de inspiração psicanalítica - e definições extremamente limitadas do que seja atuação psicológica, de forma a determinar a representação social que o público tem da Psicologia e do psicólogo ${ }^{11}$. Isto se constitui num entrave para o exercício de atividades em novas áreas que envolvem atividades para as quais o psicólogo não foi preparado como é caso do campo da assistência pública à saúde. Há, portanto, uma valorização demasiada do psicólogo enquanto profissional liberal, e autônomo durante a sua formação, de forma a definir a profissão para o público externo e se constituir em forte pólo de atração para os que buscam a profissão, fato que tem como conseqüência a hegemonia desse modelo nos cursos de Psicologia e sua impregnação em outros campos de atuação diferentes da clínica. Daí decorre também o enfoque predominante sobre o indivíduo e nos seus aspectos intrapsíquicos, tendo por base 
um modelo teórico-técnico que tem como pressuposto básico uma concepção naturalizada de subjetividade: o sujeito psicológico. Segundo Mancebo (1996), há na formação do psicólogo

uma prevalência do ensino teórico e de técnicas visando a construção de profissionais, cujas subjetividades individuadas estejam aptas à constante observação, avaliação e normatização das intimidades, com o objetivo de reconduzir futuros clientes ao modelo individualista predominante nas sociedades modernas (p. 72)...Assim, o psicólogo se auto-apresenta e é percebido como agente da "nova felicidade", enquanto um dos artífices de uma subjetividade organizada em torno da liberdade interior, da intimidade. Amplia seu campo de ação a situações de vida ditas normais, valorizando a auto-reflexão e o constante escrutínio do sujeito individuado (p. 74).

Isto, na minha opinião, revela a adesão do psicólogo às idéias e valores individualistas, de forma que o seu saber e sua prática são voltados para a intimidade e privacidade dos indivíduos, além de caracterizar um dos aspectos mais importantes da sua cultura profissional: o fato da profissão ser colada ao modo de ser do sujeito, à sua compreensão de si, mais do que em qualquer outra, como foi apontado por Russo (1993). Disto resulta a crença na intransferibilidade e incomunicabilidade dos seus conhecimentos, já que oriundos da sua experiência pessoal e subjetiva, da sua trajetória singular, do seu percurso teórico. Isto é que leva Russo (1993) a falar de uma forma particular de transmissão dos conhecimentos, da formação iniciática e do caráter de seita que existe no campo das terapêuticas, onde o estudante precisa se submeter aos procedimentos técnicos psicoterápicos para ter acesso aos princípios específicos do conhecimento e da prática. Da mesma forma, Langembach e Negreiros (1988) apontam para uma outra consequiência dessa característica do campo das psicologias: o psicólogo vive uma eterna busca de aperfeiçoamento não só na aquisição contínua de saber, mas no nível interno, pessoal, levando-o a uma eterna formação e consumo dos serviços psicológicos tais como supervisões, grupos de estudo, psicoterapias, entre outros. Isto aponta, ao meu ver, para uma forma particular de relação que o psicólogo mantém com o conhecimento - enquanto auto-revelado e produto 
singular de sua pessoa - que termina concretizando-se "numa barreira profunda à troca de saberes e a práticas interprofissionais colaborativas e flexíveis", tal como é entendido por Vasconcelos (1997, p. 29). Penso que a dificuldade encontrada pelos psicólogos em participar das equipes multiprofissionais e dos programas públicos de saúde, deve-se em parte à crença na superioridade do seu conhecimento - capaz de tudo explicar -, à confiança no "cada um por si” e na pequena disponibilidade para refazer suas ações com base num conhecimento compartilhado com diferentes profissionais e usuários dos serviços públicos, conhecimento que é sempre provisório.

Esta ênfase na singularidade de cada psicólogo, de cada percurso e experiência individual de cada um, tem ressonância também quando pensamos a questão da identidade profissional do psicólogo que parece ser cada vez mais difícil de ser definida. A diversidade constitutiva desse "ser psicólogo" não permitiria a criação de uma identidade única para a categoria (Figueiredo, 1993). Isto talvez possa servir de ponto de partida para entendermos a fragilidade e pouca representatividade dos nossos conselhos, sindicatos e associações, o fato de não terem público, já que a diversidade faz com que estas entidades consigam ser pouco representativas dos interesses da categoria, a não ser de segmentos bem específicos ou em situações em que há uma ameaça externa aos interesses e estabilidade da corporação como um todo.

Em suma, considero que as idéias e valores individualistas são hegemônicos e constitutivos da cultura profissional do psicólogo no Brasil, o que vem determinar sua adesão ao modelo de atuação liberal privatista e ao referencial psicanalítico, assim como vem delinear um estilo de recrutamento e formação nas universidades e certos padrões de relacionamento entre os pares. Isto faz com que a imagem social da profissão seja associada à prática psicoterápica individual na busca de ajustamento. Vejamos agora as implicações que isto tem para a assistência pública à saúde.

Implicações da "cultura profissional” do psicólogo sobre sua prática no campo da assistência pública à saúde

Meu objetivo nesta última parte do trabalho é refletir acerca de alguns impasses vividos pelo psicólogo no campo da assistência 
pública à saúde, decorrentes da sua cultura profissional, onde subjazem as idéias e os valores da ideologia individualista, bem como um modelo específico de subjetividade: o sujeito psicológico. $\mathrm{O}$ modelo clínico de atuação privada hegemônico entre os psicólogos - a psicoterapia individual de base psicanalítica - é geralmente transposto para o setor público, tanto para postos, centros e ambulatórios de saúde, independentemente dos objetivos dos mesmos e da população neles atendidas, tendo algumas conseqüências importantes, entre as quais destaco:

a. Conflito com as representações de Pessoa, saúde e doença, corpo, próprias aos usuários das instituições públicas de saúde;

b. Baixa eficácia das terapêuticas e alto índice de abandono dos tratamentos;

c. Seleção e hierarquização da clientela;

d. Psicologização de problemas sociais.

Quando o psicólogo passa a trabalhar nas instituições públicas de saúde, ele se depara com uma clientela e com um tipo de demanda que difere substancialmente das que ele atende na clínica privada. A clientela passa a ser constituída pela população de baixa renda, sendo geralmente encaminhada por outra instituição ou profissional de saúde, de maneira que chega com expectativas bastante distintas daquelas próprias à clientela que busca atendimento no consultório privado. Esta estaria mais em busca de "se conhecer", de "se tratar", ao passo que a clientela pública teria como objetivo a "eliminação de sintomas".

Assim, uma das primeiras dificuldades com que o psicólogo se depara no serviço público de saúde diz respeito ao comportamento da clientela diferir do que era por ele esperado, ou seja, ele se depara com um grande número de faltas às consultas, atrasos freqüentes, dificuldades de comunicação, resultados aquém dos pretendidos, além de um grande número de abandono dos tratamentos; comportamento que na maioria das vezes é atribuído à falta de interesse ou capacidade de compreensão dos pacientes para a tarefa terapêutica. Além disto, o psicólogo se vê diante de problemas que escapam ao domínio específico da clínica, referentes às condições de vida da população, as quais têm implicação nos problemas trazidos até a instituição de saúde. 
Porém, essa mudança de clientela e de demanda não seriam problemáticas se o profissional não esbarrasse em limitações teóricas e técnicas específicas de sua formação, aportes que fundamentam seus modelos de atuação, sua identidade e cultura profissional. Ou seja, estes impasses decorrem, em grande parte, da predominância no campo da Psicologia de enfoques em que o indivíduo é tratado como um ser abstrato e a-histórico, desvinculado do seu contexto social, como se todos os membros da espécie humana fossem iguais em qualquer época, em qualquer lugar (Bezerra, 1992; Spink, 1992). A Psicologia, já vem sendo caracterizada como um campo de saber marcado por teorias essencialistas e universalistas em relação ao modelo de família, de mulher, sexualidade, casamento e certas representações como a de sofrimento psíquico, corpo, entre outras. Possuímos também uma determinada idéia - tida como universal - do que seja saúde e doença, suas causas e possibilidades de tratamento e cura, que na verdade nem sempre é compartilhada por todos os segmentos sociais. Isto, conseqüentemente, tem repercussões em termos da eficácia do atendimento dispensado às populações que freqüentam as instituições públicas de saúde.

Cabe lembrar que foi no seio da Antropologia que surgiram os primeiros questionamentos em relação à universalidade destes modelos e representações acima referidos e uma primeira tentativa de “desnaturalizá-los”, mostrando que saúde, doença, corpo, morte, não se reduzem a uma evidência orgânica, natural, objetiva, mas estão intimamente ligadas às características de cada cultura e, enquanto questões humanas, só podem ser compreendidas quando articuladas com os aspectos histórico-culturais de uma sociedade (Minayo, 1993). Certamente uma das grandes contribuições que o saber antropológico realizou no campo da saúde foi mostrar que cada sociedade tem um discurso próprio sobre o corpo, saúde e doença, o qual pode variar não só através dos tempos, mas entre as classes sociais.

Como nos diz Rodrigues (1992),

Cada cultura "modela" ou "fabrica" à sua maneira um corpo humano. Toda sociedade se preocupa em imprimir no corpo, fisicamente, determinadas transformações, mediante o qual o cultural se inscreve e se 
grava sobre o biológico... $\mathrm{O}$ homem não tem um corpo único ao qual esteja para sempre confinado. Esse corpo é muito mais do que algo intrinsecamente ordenado; ele faz parte do universo convencional como qualquer outro objeto vivido ou concebido por humanos (p. 141).

Boltanski (1989), por sua vez, aponta a interação entre as formas de expressão da doença, linguagem e classe social. A idéia de "cultura somática", entendida enquanto um código de conduta corporal ou "código de boas maneiras para viver com o corpo" (p. 146), próprio dos membros de um grupo social particular, é importante para entendermos os percalços surgidos entre profissionais e pacientes no campo da saúde, pois o fato de pertencerem a diferentes grupos sociais, implica em portarem diversas culturas somáticas, isto é, diferentes "habitus corporais". Para ele um habitus corporal poderia ser definido da seguinte forma:

É um sistema de regras profundamente interiorizadas que, sem nunca serem exprimidas na totalidade, nem de maneira sistemática, organizam implicitamente a relação dos indivíduos de um mesmo grupo com seus corpos e cuja aplicação a um grande número de diferentes situações permite a produção de condutas físicas diferentes e diferentemente adaptadas a essas situações, mas cuja unidade profunda reside no fato delas permanecerem sempre conformes com a cultura somática daqueles que a produzem (p. 176).

Em outras palavras, a relação que os indivíduos mantêm com seus corpos, a forma de habitar, expressar e verbalizar as sensações corporais, tudo isso é fruto de um habitus corporal, de um conjunto de práticas sociais características de uma classe, logo escapam a qualquer tentativa de universalização e padronização. Estas questões são importantes pois nos ajudam a compreender os inúmeros impasses e identificar as raízes de um certo mal-estar estabelecido entre pacientes e terapeutas no campo da assistência pública à saúde, bem como a baixa eficácia das terapêuticas e o alto índice de abandono dos tratamentos por parte dos pacientes.

A diversidade cultural entre psicólogos e os usuários dos serviços públicos de saúde, pertencentes geralmente a diferentes grupos sociais, também tem implicação no que tange ao modelo de subjetivi- 
dade próprio de cada um. Como tentei mostrar, os profissionais de Psicologia estão norteados pela representação do sujeito psicológico, a qual constitui um desdobramento do indivíduo moderno, marcado pela privatização dos sentimentos e por uma ênfase na sua interioridade psicológica. Já a cultura das classes populares brasileiras, tal como foi apontado na nossa literatura ${ }^{12}$, está predominantemente marcada por uma específica noção de Pessoa, a qual pressupõe uma visão de mundo hierárquica (oposta à igualitária) e holista (oposta à individualista). Em outras palavras, o modelo de subjetividade próprios aos pacientes que compõem a clientela que utiliza os serviços públicos de saúde, em muito se diferencia do modelo psicológico dos terapeutas e da classe média em geral, pois se trata de uma subjetividade relacional e situacional, isto é, a forma do indivíduo ver, estar e se colocar no mundo se constrói diferentemente de uns para os outros de acordo com a posição ocupada na totalidade social. Em outras palavras, tais populações são caracterizadas por um ideário onde a coletividade, as tradições e os costumes, a rede de reciprocidade e de solidariedade condicionam as existências individuais. Com isso não quero dizer que as comunidades holistas estejam imunes às formações ideológicas e subjetivas individualistas. Nada mais falso. Afirmo apenas que nesses lugares predominam as formações holistas.

Estes diferentes modelos de subjetividade implicam em concepções diversas de causalidade e cura das doenças - pois ancoradas em diferentes culturas somáticas - e em diferentes expectativas quanto ao tratamento psicoterápico oferecido pelos psicólogos, no que diz respeito à sua necessidade e eficácia.

De acordo com Duarte (1988) e Freire Costa (1987, 1989), nas camadas populares existe uma maneira própria de expressão dos conflitos - a "doença dos nervos" - cujos fenômenos físicos-morais apontam para uma imbricação do corpo e do espírito, diferenciando-se assim da racionalidade presente no modelo psicológico dominante entre os psicólogos. Aqui existe a crença de que o mal-estar, o sofrimento encontra-se no interior do sujeito, no nível dos seus sentimentos, desejos e pensamentos; ao passo que no modelo do nervoso, a localização do sofrimento está no corpo, principal veículo de expressão e comunicação das vivências. Daí a noção de cura significar su- 
pressão de sintomas e o conseqüente restabelecimento da vida normal. Já no modelo psicológico, o corpo tem um outro valor: é um corpo interiorizado, subjetivado, não mais veículo privilegiado de expressão da identidade, determinando uma forma de expressão do sofrimento descorporificada, psíquica. Neste caso, cura é sinônimo de realização afetiva, sexual, autonomia, independência e liberdade.

Quando os psicólogos transpõem suas técnicas e teorias psicológicas para o atendimento das camadas populares, partem do pressuposto que esta população compartilha da mesma visão de mundo, que ela tem as mesmas representações de saúde/doença, corpo etc., e o mesmo modelo de subjetividade que fundamenta suas formas de atuação. Isto se deve ao fato de que partem de uma perspectiva universalista-essencialista em torno da natureza humana e de uma crença na eficácia intrínseca dos procedimentos psicoterápicos de qualquer natureza. Desta forma, ficam inabilitados para perceber que nem sempre esse arsenal teórico-técnico é adequado para as ações específicas do campo da assistência pública à saúde e para a clientela que freqüenta estas instituições. Ou seja, as diferenças de classe e cultura impõem uma diversidade cultural entre profissionais e pacientes, a qual resulta freqüentemente em intervenções e estratégias de ação descontextualizadas e etnocêntricas. Autores como Vilhena, (1993), chegam a mencionar a produção, em termos de discurso e prática, de um verdadeiro apartheid clínico, que tende a patologizar e ver negatividade e faltas essenciais onde provavelmente existem apenas diferenças culturais.

Alguns estudos (Figueira, 1978; Ropa \& Duarte, 1985) baseados nas contribuições de Bourdieu e Boltanski, tiveram a preocupação de apontar que as práticas psicoterápicas pressupõem, a existência de certas categorias tais como "reflexividade", "esprit d'examen" e "problematização" "13 nos indivíduos, bem como de uma congruência entre os sistemas simbólicos dos terapeutas e pacientes, isto é, que eles compartilhem uma visão de mundo, a crença no saber diagnóstico e na eficácia terapêutica, para que tenham sucesso ou eficácia simbólica.

Segundo Figueira (1978), toda prática terapêutica só é eficaz se ela funciona enquanto sistema simbólico para o indivíduo, ou seja, se ela é capaz de lhe oferecer uma explicação, um sentido para o seu 
sofrimento e suas vivências. Quando a Psicanálise, por exemplo, fornece uma explicação para um estado de sofrimento e uma maneira de se aliviar dele, ela está apoiada numa visão de mundo que lhe é própria; e para que ela seja eficaz enquanto terapêutica, é preciso que seja congruente com o modo dos indivíduos afetados pensarem a si mesmos.

Em outras palavras, é preciso que terapeutas e pacientes compartilhem de um mesmo "projeto psicoterápico"14, o qual se fundamenta em quatro noções fundamentais: causalidade, cura, tempo-memória e indivíduo. Ou seja, pacientes e terapeutas devem partilhar das mesmas idéias de causalidade e cura, acreditar que estão nas experiências passadas as raízes do seu sofrimento atual e, se auto-representar como um indivíduo autônomo, dotado de uma interioridade, capaz de mudar o curso da sua história.

Inseridos em diferentes contextos culturais, com diferentes visões de mundo, terapeutas e pacientes geralmente não compartilham de um mesmo projeto terapêutico. Daí, ser muito freqüente os casos de abandono de tratamento pela população, que não vê sentido nas técnicas e procedimentos típicos das psicoterapias, se configurando como um arsenal que não funciona terapeuticamente para elas. Por outro lado, também ocorre uma seleção e hierarquização da clientela nos serviços públicos de saúde ${ }^{15}$ : aqueles que possuem um modo de expressão do sofrimento e uma subjetividade próprios ao modelo da escuta terapêutica, isto é, têm uma demanda subjetiva, são os clientes mais valorizados pelos psicólogos; ao passo que aqueles se expressam pela via do nervoso e não compartilham das mesmas idéias de causa e cura do seu sofrimento, nem o modelo de subjetividade, ou seja, têm uma demanda mais objetiva, são desqualificados, como se houvesse um desinteresse ou incompetência por parte deles para realizar um tratamento psicoterápico nos moldes tradicionais. Desta forma, passam a engrossar as filas dos psiquiatras e são alvo de intervenção medicalizante.

Nicácio (1994), pensando sobre a estratificação da clientela chega a conclusão que:

O direcionamento seletivo dos pacientes para o serviço de Psicologia obedece a um critério de eficácia e produtividade. Tendo-se em vista a 
grande demanda que aflui ao ambulatório, devem ser selecionados aqueles casos para os quais, segundo se supõe, a escuta psicoterápica se mostrará eficaz. Enquadram-se neste preceito os pacientes do grupo dos sujeitos psicológicos... Já os pacientes do fluxo do nervoso seriam refratários ao dispositivo de atendimento psicoterápico, de modo que seria contraproducente investir tempo neste grupo (p. 102).

O que não se percebe, segundo Vasconcelos (1997) e Nicácio (1994), é que geralmente o sujeito psicológico pertence à classe média e o "nervoso" à classe popular, ou seja, que a hierarquização e seleção da clientela passa também pelo critério de pertencimento a uma determinada classe social. Estas escolhas terminam refletindo os valores hegemônicos em nossa sociedade e desqualificando os diferentes modos de expressão do sofrimento e modelos de subjetividade.

Por fim, uma outra consequiência da cultura profissional do psicólogo no campo da assistência pública à saúde diz respeito à psicologização dos problemas sociais, tal como me referi anteriormente. Isto significa que o psicólogo deixa de fora na sua análise as dimensões culturais, históricas e políticas dos comportamentos. Ele se atém exclusivamente ao domínio da sua especialidade, favorecendo mais ainda a fragmentação dos saberes e serviços na instituição de saúde. Assim, termina por limitar cada vez mais sua atuação às técnicas próprias à sua disciplina, seu espaço concreto de atuação ficando, conseqüentemente, mais isolado dos outros profissionais e da comunidade.

\section{Referências}

Bezerra Jr., B. (1982). A noção de indivíduo: sobre um implícito pouco pensado. Dissertação de mestrado não-publicada, Universidade Estadual do Rio de Janeiro, Rio de Janeiro.

Bezerra J., B. (1989). Subjetividade moderna e o campo da Psicanálise. In J. Birman (Org.), Freud: 50 Anos Depois (pp. 219-239). Rio de Janeiro: Relume-Dumará.

Bezerra J., B. (1992). Considerações sobre terapêuticas ambulatoriais em saúde mental. In S. A.Tundis \& N. R. Costa (Orgs), Cidadania e loucura: políticas de saúde mental no Brasil (pp. 133-169). Petrópolis: Vozes.

Boltanski, L. (1989). As classes sociais e o corpo. Rio de Janeiro: Graal.

Botomé, S. P. (1996). Serviço à população ou submissão ao poder: o exercício do controle na intervenção social do psicólogo. Estudos de Psicologia (UFRN), 1, 173-202. 
Caniato,A. (1988). Implicações do enfoque social na prática do psicólogo em saúde mental. Psicologia e Sociedade, III (4), 178-188.

Castel, R. (1989). A gestão dos riscos: da antipsiquiatria à pós-psicanálise. Rio de Janeiro: Francisco Alves.

Coimbra, C. M. B. (1993). A produção de subjetividade nos anos 70 no Brasil e as práticas "Psi". In J. F. Silva Filho \& J. Russo (Org.), Duzentos Anos de Psiquiatria (pp. 59-70). Rio de Janeiro: Relume-Dumará.

Conselho Federal de Psicologia (Org.) (1988). Quem é o psicólogo brasileiro? São Paulo: Edicon.

Conselho Federal de Psicologia (Org.) (1992). Psicólogo brasileiro: construção de novos espaços. Campinas: Átomo.

Conselho Federal de Psicologia (Org.) (1994). Psicólogo brasileiro: práticas emergentes e desafios. São Paulo: Casa do Psicólogo.

Deleule, D. (1972). La Psicología, mito científico. Barcelona: Anagrama

Dias, M. A. (1994). Mal-estar no serviço público: um estudo sobre a inserção do psicólogo num programa de saúde mental do Rio de Janeiro. Dissertação de mestrado não-publicada, Pontifícia Universidade Católica do Rio de Janeiro, Rio de Janeiro.

Duarte, L. F. D. (1988). Da vida nervosa nas classes trabalhadoras urbanas. Rio de Janeiro: Jorge Zahar.

Dumont, L. (1985). O individualismo: uma perspectiva antropológica da sociedade moderna. Rio de Janeiro: Rocco.

Figueira, S. A. (1978). Notas introdutórias ao estudo das terapêuticas I. In S. A. Figueira (Org.), Sociedade e Doença Mental (pp. 87-148). Rio de Janeiro: Campus.

Figueira, S. A. (1985). Introdução: psicologismo, Psicanálise e Ciências Sociais na "cultura psicanalítica". In S. A. Figueira (Org.), Cultura da Psicanálise (pp. 7-13). São Paulo: Brasiliense.

Figueira, S. A. (1986). O "moderno" e o "arcaico na nova família brasileira: notas sobre a dimensão invisível da mudança social. In S. A. Figueira (Org.), Uma nova família? O moderno e o arcaico na família de classe média brasileira (pp. 11-30). Rio de Janeiro: Jorge Zahar.

Figueiredo, L. C. (1993). Sob o signo da multiplicidade. Estudos de Psicologia (Campinas), 10 (1), 11-19.

Freire-Costa, J. (1982). Projeto psicoterápico. Manuscrito não-publicado.

Freire-Costa, J. (1987). Consciência da doença como consciência do sintoma: a "doença dos nervos" e a identidade psicológica. Cadernos do IMS, 1 , pp. 4-44.

Freire-Costa, J. (1989). Psicanálise e contexto cultural. Rio de Janeiro: Campus.

Gil, A. C. (1985). O Psicólogo e sua ideologia. Psicologia, Ciência e Profissão, 5(1), 13-17. 
Guimarães, N. A. (1982). A prática da Psicologia Clínica em questão: considerações sobre a inserção social do psicólogo clínico. Dissertação de mestrado não-publicada, Pontifícia Universidade Católica do Rio de Janeiro, Rio de Janeiro.

Langembach, M., \& Negreiros, T. C. G. (1988). A formação complementar: um labirinto profissional. In Conselho Federal de Psicologia (Org.), Quem é o Psicólogo Brasileiro? (pp. 86-99). São Paulo: Edicon.

Lo Bianco, A. C. (1993). A constituição do campo "psi”: algumas considerações. In J. F. Silva Filho \& J. Russo (Org.), Duzentos anos de Psiquiatria (pp. 47-52). Rio de Janeiro: Relume-Dumará.

Mancebo, D. (1996). História dos cursos de Psicologia no Rio de Janeiro (1956-1979): a cultura psicológica nas instituições de ensino superior. Manuscrito não-publicado.

Mancebo, D. (1997). Da Psicologia Aplicada à instituição universitária: a regulamentação da Psicologia enquanto profissão. Cadernos do IPUB, 8 , 161-177.

Martín-Baró, I. (1997). O Papel do Psicólogo. Estudos de Psicologia (Natal), 2, 7-27.

Massimi, M. (1990). História da Psicologia no Brasil. São Paulo: EPU.

Massimi, M. (1996). Estudos históricos acerca da Psicologia brasileira: uma contribuição. In R. H. F. Campos (Org.), Coletâneas da ANPEPP, 1(15), 79-94.

Minayo, M. C. S. (1993). O desafio do conhecimento: pesquisa qualitativa em saúde. São Paulo, Rio de Janeiro: Hucitec/Abrasco.

Nicácio, E. M. (1994). Agenciamentos sociais, subjetividade e sintoma: a seleção hierarquizada da clientela de um ambulatório de saúde mental. Dissertação de Mestrado não-publicada, Universidade Estadual do Rio de Janeiro, Rio de Janeiro.

Richelle, M. (1968). Pourquoi les psychologues? Bruxelles: Charles Dessart.

Rodrigues, J. C. (1992). Ensaios em Antropologia do Poder. Rio de Janeiro: Terra Nova.

Ropa, D., \& Duarte, L. F. D. (1985). Considerações teóricas sobre a questão do atendimento psicológico às classes trabalhadoras. In S. A. Figueira (Org.), Cultura da Psicanálise (pp. 178-201), Rio de Janeiro: Campus.

Russo, J. A. (1993). Indivíduo e transcendência: algumas reflexões sobre as modernas "religiões do Eu". Trabalho apresentado no seminário "A religião e a questão do sujeito no ocidente", Centro João XXIII de Investigação Social, Paulo de Frontin, Rio de Janeiro.

Salem, T. (1992). A despossessão subjetiva: dos paradoxos do individualismo. Revista Brasileira de Ciências Sociais, 18(7), 62-77. 
Santos, T. C. (1990). Subjetividade e difusão da Psicanálise: uma discussão da cultura psicanalítica. Tese de Doutorado não-publicada, Pontifícia Universidade Católica do Rio de Janeiro, Rio de Janeiro.

Spink, M. J. (1992). Psicologia da saúde: a estruturação de um novo campo de saber. In F. C. B. Campos (Org.), Psicologia e saúde: repensando práticas (pp. 11-24). São Paulo: Hucitec.

Vasconcelos, E. M. (1992). The new alienists of the poor: developing community mental health services in Brazil - 1978/1989. Tese de doutorado não-publicada, University of London, London.

Vasconcelos, E. M. (1997). Desinstitucionalização e interdisciplinaridade em saúde mental. Cadernos do IPUB, 7, 19-41.

Velho, G. (1987). Individualismo e cultura: notas para uma antropologia da sociedade contemporânea. Rio de Janeiro: Jorge Zahar.

Vilhena, J. (1993). "Apartheid clínico: uma visão violenta e autoritária da prática clínica”. Cadernos do SPA: uma prática em debate. Rio de Janeiro: PUC.

Yamamoto, O. H. (1987). A crise e as alternativas da Psicologia. São Paulo: EDICON. 
estar no mundo que não se reduz a uma dimensão individual. A subjetividade é um fato social construído a partir de processos de subjetivação, o qual é engendrado por determinantes sociais - históricos, políticos, ideológicos, de gênero, de religião, conscientes ou não. Desta forma, em diferentes contextos culturais, diferentes subjetividades são produzidas.

3 "Campo psi" está sendo tomado como um conjunto de saberes (Psicanálise, Psicologia e Psiquiatria), de práticas geradas por estes saberes e, dos profissionais que nele operam (Lo Bianco, 1993).

4 Esta diferenciação foi feita por Dumont (1985) para tentar solucionar uma confusão freqüente no campo das ciências humanas entre a noção de indivíduo biológico - representante da espécie humana - e a noção de indivíduo enquanto ser moral, noção dominante e limitada à sociedade ocidental moderna.

5 Esta configuração emergiu historicamente no contexto das sociedades modernas, pelo menos em função de dois fenômenos: secularização ou dessacralização do mundo e o processo de intimização ou interiorização do eu, os quais estão intimamente ligados à expansão da ideologia individualista, tal como aponta Russo (1993). Segundo a autora, dá-se, portanto, o surgimento de uma espécie de "religião do Eu" busca de totalização via indivíduo, a qual é possibilitada pelas práticas 
118 M. Dimenstein

psicoterápicas, que buscam desvendar este Eu inteiramente e ajudar o sujeito a conviver com o desconhecimento de suas próprias determinações internas. Assim, haveria uma certa continuidade entre o indivíduo moral, autônomo e o sujeito despossuído de si, um resto de totalidade, de transcendência e completude neste Eu, ao mesmo tempo em que é anti-holista.

6 Segundo Santos (1990), podemos considerar como representações ideais "todo o conjunto de imagens que veiculadas através de discursos e práticas sociais "condensam" em "tipos ideais" as aspirações e desejos de um dado grupo social, dentro de um período histórico particular" (p. 7). A difusão destes ideais analíticos é eficaz na medida em que são representações investidas de uma promessa de felicidade, ou pelo menos, de saber lidar com as emoções e sentimentos.

7 Para Figueira (1986), a modernização acelerada levou a coexistência de antigos e novos ideais e identidades, isto é, a existência de mapas diferentes e contraditórios nos sujeitos, ou em outras palavras, a um "desmapeamento" (p. 22). Uma das consequiências disto foi a enorme procura de mapas através das psicoterapias e da própria Psicanálise. Acrescente-se a isto, o boom da criação e procura de faculdades de Psicologia, o aumento da oferta de serviços psicológicos, como também a expansão do campo de atuação do psicólogo no Brasil e do seu mercado de trabalho. 
8 Guimarães (1982) enfatiza em seu trabalho um aspecto particular do psicologismo que considero muito importante, que é enfocá-lo enquanto ação ideológica, ou seja, enquanto forma de coerção ou manipulação que tenta evitar as reações de oposição às instituições totalitárias e procura encobrir as causas e anular intervenções sócio-políticas, na medida em que psicologiza a realidade social. Isto, é o que caracteriza a formação do psicólogo no Brasil.

9 Estou me referindo genericamente aos psicólogos, psiquiatras e psicanalistas.

${ }^{10}$ É importante mencionar a que a própria literatura psi já denuncia essa universalização indevida (Bezerra Jr, 1982; Freire Costa, 1989; Ropa \& Duarte, 1985).

${ }^{11}$ Ver as pesquisas realizadas pelo Conselho Federal de Psicologia (1988; 1992; 1994) no que se refere à formação do psicólogo.

${ }^{12}$ Duarte, 1988; Freire Costa, 1987, 1989; Ropa e Duarte, 1985.

${ }^{13}$ Reflexividade é a capacidade de uma pessoa observar o próprio corpo e discriminar suas sensações corporais, transformando-as em linguagem passível de ser comunicada. Esprit d'examem se refere ao hábito de considerar que tudo é passível de ser colocado sob exame, de ser pensado. Problematização é a disposição para identificar problemas, refletir sobre eles e considerar que são fruto de alguma coisa a partir do qual foram desencade- 
Magda Dimenstein, doutora em Saúde Mental pelo Instituto de Psiquiatria da Universidade Federal do Rio de Janeiro, é professora do Departamento de Psicologia e Vice-Coordenadora do Programa de Pós-Graduação em Psicologia da Universidade Federal do Rio Grande do Norte. Endereço para correspondência: Uni- ados, seguindo um certo curso. Estas três categorias estão interligadas, dependem da inserção cultural dos indivíduos e do seu processo de socialização, logo aparecem de modo desigual nas diversas classes sociais (Ropa \& Duarte, 1985, p. 186).

${ }^{14}$ Estou me referindo ao trabalho de Freire Costa (1982), que foi trabalhado por Dias (1994) e Nicácio (1994) em suas dissertações de mestrado; bem como por Bezerra (1982), que traz uma discussão sobre o tema e onde se refere ao "projeto psicoterápico" como sendo um conjunto de expectativas sobre o andamento e resultados do processo psicoterápico comum entre terapeutas e pacientes.

${ }^{15}$ Este tema foi bastante trabalhado por Vasconcelos (1992) e Nicácio (1994) de uma forma bem mais aprofundada do que está sendo feita aqui.

Sobre a autora 
versidade Federal do Rio Grande do Norte, Centro de Ciências Humanas, Letras e Artes, Departamento de Psicologia, sala 607, Campus Universitário, 59.078970, Natal, RN. Tele/fax: $(0 * * 84)$ 213-1739,

e-mail:

magdad@uol.com.br 